
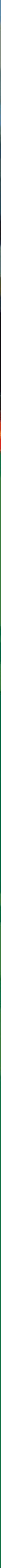


\section{6 \\ Tourism crisis: Management and recovery in tourist-reliant destinations}

\section{Yetta Gurtner}

Tourism and travel for leisure are by no means new pursuits. With technological innovations and increased discretionary income over the past sixty years, such activities have rapidly generated a global industry. Renowned for stimulating social and economic growth tourism has also become a motivational force for development in many diverse locations. As a destination or specific host-community becomes more reliant on the opportunities and revenues generated from the tourism sector, it exponentially increases its vulnerability to a potential tourism crisis. Given that the successful tourism enterprise is based on both physical and intangible qualities, the associated hazards are innumerable. Recent events such as the violent terrorist attacks in Bali highlight the relevance of crisis management strategies in facilitating the process of both community and destination recovery.

\section{Tourism and Development}

With growing access, services, opportunity and demand, tourism has rapidly become a prosperous and dynamic global industry. The World Tourism Organisation (WTO, 2002) defines tourism in the following manner:

...comprises the activities of persons travelling to and staying in places outside their usual environment for not more than one consecutive year for leisure, business and other purposes not related to the exercise of an activity remunerated from within the place visited (p. 1).

Although such a definition establishes the capacity of a tourist, it fails to elaborate on the business or occupation of tourism, including, the economics, the infrastructure and even the role of associated stakeholders. As an industry, tourism encompasses much more than the activities of the visitor. 
McIntosh and Goeldner (1986) describe tourism as an interactive process, it is "the sum of the phenomena and relationships arising from the interaction of tourists, business suppliers, host governments, and host communities in the process of attracting and hosting these tourists and other visitors" (p. 4). Tangible elements include transport, accommodation, food, environment and entertainment facilities, while the more intangible elements may involve culture, hospitality, ambience and relaxation. With increasing foreign exchange earnings and revenues over the past few decades, tourism has become the world's largest growth industry, comprising over $10.6 \%$ of global GDP and generating the equivalent of one in every twelve jobs (World Travel and Tourism Council, WTTC, 2005).

Given such lucrative fiscal and employment potential, tourism has been widely promoted as a catalyst for economic and social development. As a labour intensive industry, a successful tourism endeavour can create significant income and job opportunities in both the formal and informal sectors. Associated investments often stimulate new and improved infrastructure, including transport networks, utilities, sanitation and medical facilities. While many facilities are intended to advance tourism prospects, such services may also improve the general standard of living for proximate residents. Governments can also profit because of related trade opportunities, foreign receipts and tax revenues generated through travel and tourism. As a source of such opportunities, the promotion and development of tourism has proved attractive to many destinations whether at the country, state, region, city or town level (Bierman, 2003).

\section{Tourism-reliant destinations}

While the nature of tourism in any locality depends on both dynamics and scale, much of the industry appears to have been developed with limited consideration to long-term sustainability (UNEP, 2002). In many destinations, particularly within developing nations, rapid and uncontrolled growth of the tourism sector has already resulted in significant social, cultural and environmental consequences. Although tourism enterprise may generate tangible financial prosperity for many stakeholders, growing dependence on such trade can actually increase the risks of experiencing future adversity.

Lured by the apparent economic prospects and incentives, individuals, businesses, service providers and even the governments within host communities often realign activities to conduct and openly support tourism. More traditional pursuits such as agriculture and manufacturing may be abandoned in favour of tourism-related employment, and consequently the economy becomes increasingly less diversified. Pertinent resources, both 
natural and cultural, are often appropriated as a consequence of tourist demands, with limited public consultation or future recourse. The more a destination becomes contingent on the demands and fortunes of the tourism industry without consideration to sustainable development, the greater the level of socio-economic vulnerability (Glaesser, 2003).

\section{The vulnerability of tourism}

Historically, tourism development has proved to be a sensitive, erratic and precarious undertaking. It is in its capacity to offer so many options and easily accommodate changes in consumer desires, that the fragility of the tourist market and the vulnerability of dependant destinations are revealed. As a voluntary activity, travellers have the discretion to simply cancel plans, postpone trips or opt for alternative destinations. The motivations behind variations in market demand can be diverse as economics, trends or even a shift in demographics. However, the research conducted by numerous academics and industry professionals (Cavlek, 2002; Pizam \& Mansfield, 1996) have clearly established that sudden and radical adjustments to travel plans are regularly instigated by a change in destination image and public perceptions of safety and risk.

In their book Tourism, Crime and International Security, editors Pizam and Mansfield (1996, p. 1) reassert the popular premise that "safety, tranquillity and peace are a necessary prerequisite for prosperous tourism". While there are many elements that may influence destination choice, consumer decisions are strongly based on an assessment of the level of personal risk (Bar-On, 1996). The perceived risks may entail the chance of disruption of planned activities, crime, property loss and/or damage, exposure to danger, injury or even death. A variety of external factors including media coverage, travel advisories, business, economics, peer pressure and insurance policies; may also help persuade or prejudice the subjective process of risk assessment and evaluation. The more a destination is publicly associated with an adverse threat or hazard, whether real or perceived, the greater the likelihood of consumers making alternative arrangements.

\section{Tourism and hazards}

There have been numerous typologies regarding the sources of risks for tourism businesses and destinations (WTO, 2003; PATA, 2003; Shaluf, Ahmadun \& Said, 2003; Faulkner, 2001), however, much of the popular literature employs the generic classifications of natural, human induced and technological hazards. A natural hazard may be climatological (e.g. flood, drought, extreme cold, hurricane, cyclone, wildfire) or geophysical (e.g. earthquake, volcanic eruption, landslide, avalanche, tsunami). Human- 
induced events are as varied and diverse as transport accidents, crime, political instability, terrorism, war, industrial action and epidemic diseases. Although not as widely covered in tourism studies, technological hazards may entail mechanical/systems failure, industrial and even nuclear accidents. If it had been substantiated the Y2K (millennium bug) had the potential to disrupt computer travel and booking procedures, transport and navigational equipment and even the supply of amenities on an almost global scale.

While the threat of any such hazard agent may generate public apprehension, a hazard does not necessarily result in a definitive "event" or incident. With adequate warnings, preparation and contingency plans it may be possible to avert or eliminate a prospective hazard, or to effectively minimise the level of actual damage sustained. Irrespective of the level of awareness or planning however, experience consistently demonstrates that not all hazards may be accurately forecast or avoided (Faulkner, 2001).

Given the complex social, economic and environmental context in which a host community fosters tourism development, the impacts and consequence to a hazard-afflicted tourist destination can be highly unpredictable and highly differential. An environment of physical exposure, poverty, high urbanisation, poor social dynamics and unsafe conditions (vulnerability) typically enhance both the degree and severity of adverse impacts (WHO/EHA, 2002).

Tourists themselves are often more susceptible to direct danger due to reduced alertness, limited local hazard knowledge and less familiarity with the resources that can be relied upon to ensure their personal safety (Faulkner, 2001). In an emergency situation, immediate response and relief efforts are generally determined by the extent of local coping capacity and resources.

Direct hazard impacts may include injuries, fatalities, evacuation, extensive damage (physical, environmental and social) and substantial economic costs (Shaluf, Ahmadun \& Said, 2003). The scope may be localised to a single business, destination, or affect an entire geographic region. Beyond the more apparent physical effects, many hazard agents also generate indirect and 'ripple effect' consequences which can lead to longer-term issues. Associated reconstruction costs and travel market instability has the potential to generate significant social and economic repercussions for any tourist-reliant operatives. Depending on the variables measured, evaluative criteria, and conceptual definitions applied, such hazard events have been variably referred to as accidents, emergencies, disasters and/or crises (Shaluf, Ahmadun \& Said, 2003). 


\section{Tourism crisis}

Rather than employing a definitive scale or quantitative approach, the WTO (2003) defines crisis (as it pertains to tourism) as "any unexpected event that affects traveller confidence in a destination and interferes with the ability to continue operating normally" (p. 1). Sonmez, Apostolopoulos and Tarlow (1999) utilise the more comprehensive term of 'tourism crisis' to describe circumstances:

which can threaten the normal operation and conduct of tourismrelated businesses; damage a tourist destination's overall reputation for safety, attractiveness, and comfort by negatively affecting visitor's perceptions of that destination; and, in turn, cause a downturn in the local travel and tourism economy and interrupt the continuity of business operations for the local travel and tourism industry, by the reduction in tourist arrivals and expenditures...

(pp. 13-14).

Given such definitions, it becomes evident that unlike an accident, emergency or disaster, a tourism crisis is not necessarily precipitated by the threat of a real and imminent danger, or the direct physical impact of a hazard agent. While natural and human-induced incidents seem to be the most abundant instances, tourism crisis may be triggered by external and less tangible factors that adversely affect destination image, such as proximate regional instability, rumour and bad publicity. As it remains feasibly and logistically impossible to insulate against every such contingency, no tourism destination can ever be completely immune from crisis (Bierman, 2003).

While the repercussions of the tragic terrorist attacks of September 2001 and outbreak of SARS (Sudden Acute Respiratory Syndrome) confirm that the entire tourism industry is sensitive to the turbulence and instability of crisis, some destinations and host communities remain more disposed to experience adversity. Although it is impossible to eliminate every risk, it is apparent that to minimise susceptibility to such crises, such destination stakeholders need to implement greater initiatives towards vulnerability reduction, consistent with effective crisis management.

\section{Developing tourism crisis management strategies}

The relative frequency and high profile of such recent international events has resulted in increasing industry and academic attention towards the promotion of tangible tourism-based crisis management strategies. Based 
on an amalgam of disaster and business management principles such initiatives are intended to minimise any negative destination impacts and help retain the confidence of both travellers and the travel industry (WTO, 2003; Bierman, 2003; PATA, 2003). As with an integrated disaster management approach, a tourism crisis management framework is generally premised on the continuum of risk reduction and response (refer to Figure 6.1). While the terminology often varies, the proactive phases before the 'crisis trigger' include assessment, prevention/reduction, mitigation and readiness/preparedness. Post-event stages include response/relief, rehabilitation, and recovery/reconstruction.

Ideally, the experiences and lessons learnt from any preceding crisis would be used in mitigating future contingencies.

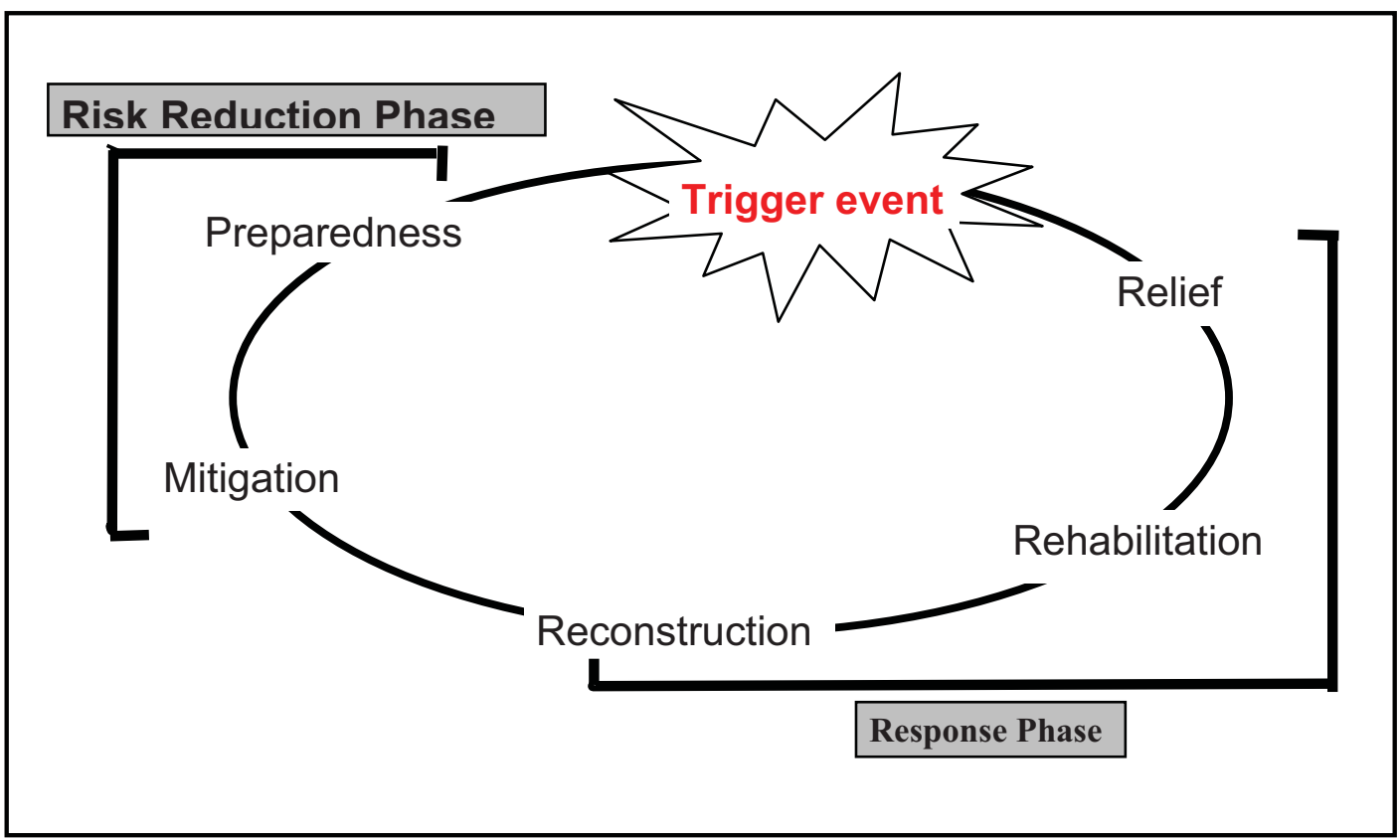

Figure 6.1 The crisis management continuum

Source: Adapted from WHO/EHA, 2002

Founded on extensive industry experience PATA's (2003) generic planning guide Crisis: It won't happen to us! reveals that in the case of tourism, the nature of the event/issue, visibility, the number, age and prominence of people involved, and the level of associated media attention commonly influences the extent and duration of subsequent crises. Given the importance of maintaining a low risk perception and positive image, similar popular destination crisis management plans also highlight facets of communications, safety and security, market research and promotion (WTO, 2003). While formal crisis management initiatives are often resourced and 
planned at the business, government or organisational level, a holistic approach suggests that the development of a comprehensive strategy for the tourism sector be co-ordinated between all relevant stakeholders (Sonmez, et al., 1999; Cavlek, 2002).

Cavlek (2002) and Sonmez et al. (1999) counsel that at a minimum, a destination management task force should include government officials, relevant travel, tourism and hospitality professionals (domestic and foreign), and community leaders. They further elaborate that an effective and operational plan requires dedication to destination improvement/recovery, the ability to exercise appropriate authority, and access to adequate resources and financial assistance. While disaster researcher Quarantelli (1998) proposes that this process of active cooperation and preparation is inherently more valuable than the production of a written plan, some tourism proponents recommend the creation of a tourism specific crisis management guidebook detailing relevant contacts, responsibilities, agreed terminology, useful sample/templates and communications strategies (Sonmez, et al. 1999). Irrespective of the preferred methodology, most researchers agree that crisis management endeavours are best instigated before the advent of a significant hazard.

\section{Crisis risk reduction and mitigation}

Based on the experience of countless complacent and ill-prepared destinations that have faced a substantial tourism crisis, the majority of tourism scholars and industry authorities now promote a proactive approach to crisis management, beginning with risk assessment (WTO, 2003; WTTC, 2003; Gee \& Gain, 1986; Sonmez et al., 1999; Glaesser, 2003). Employing various methodologies and means of data analysis, mapping and monitoring, such an assessment generally involves an evaluation of risk relative to hazard probability and destination vulnerability. With the existing context as a foundation, such calculations should also deliberate on any potential physical (environment), social and economic impacts, including anticipated losses.

In distinguishing and prioritising all conceivable hazards that may have a negative effect on a destination, the risk management process is intended to generate strategies and initiatives to minimise potential impacts. Proposed structural measures (WHO/EHA, 2002) may involve enforced compliance with minimum building standards, effective zoning and infrastructure redevelopment, such as transportation networks, airports and medical facilities. Other policies may include partnering with law enforcement officials (Sonmez et al., 1999) (e.g. tourist police and foreign intelligence 
sharing), coordination with media outlets and improved community awareness and education.

Sonmez et al. (1999) again propose that the development and dissemination of a clear, comprehensive, crisis management plan/guidebook is one of the best visible indications of a destination's preparedness. The essence of proactive risk reduction, mitigation and preparation is that all feasible contingencies, including appropriate training, warnings and evacuation plans need be regularly addressed and practised. Less formalised procedures may include public education and enhancing local response capabilities, flexibility and confidence. Where written documents may exist it is advised that details are consistently monitored and reviewed for both relevance and accuracy. Even though such crisis management planning may be developed within the context of the tourism sector, it is important that any measures and actions undertaken are consistent with broader scale emergency/disaster management operations.

\section{Crisis response}

Contrary to the recommendations made as early as the mid-1980s (Gee \& Gain, 1986), the majority of popular tourist destinations still don't appear to have adequate or effective crisis management planning (Faulkner, 2001; Beirman, 2003). Many places, particularly in the developing world, continue to lack the skills, resources and capacity to efficiently deal with the onset and impacts of any major hazard. In such cases, the reality of a crisis often becomes the catalyst for developing inexperienced, reactive strategies.

While emergency relief and response prioritises the protection of life and property in dangerous situations, activities undertaken by the tourism sector in the first 24 hours of a crisis are considered crucial (WTO, 2003; WTTC, 2003). Irrespective of the level of perceived damage or destruction, responsible management requires the maintenance of credibility. Most destination case studies support the assertion that honesty, transparency, professionalism and good communications with both public and media can facilitate faster recovery (WTO, 2003; PATA, 2003; Ritchie, 2004). To minimise uncertainty, it is recommended that authorities establish a respected spokesperson to immediately address any concerns regarding safety and security, and effectively relay both the facts and pertinent issues. Beyond any negative imagery and sensationalism by the popular media, competent public relations can help provide balance and direction.

When triggered by a tangible hazard agent, the duration of the subsequent emergency period is determined by the context, type, scope, speed of onset, and direct impacts of the event (WHO/EHA, 2002). If the situation is 
beyond a community's capacity to cope, the destination may require the urgent assistance of external agencies and organisations. Standard response strategies include the establishment of an emergency operations centre with an adjunct media/public relations facility. Less critical rehabilitation strategies, which may include clearance of debris, utilities restoration, facilitating job returns and resumption of commerce, can take weeks or even months. Disputed issues of insurance, liability, ownership and jurisdiction also often cause delays.

Beyond the immediate concerns regarding physical infrastructure, direct losses or operational capabilities, to retain visitor numbers and expenditure a significantly damaged tourism sector is likely to require rapid and extensive recovery strategies (Cavlek, 2002). Without tourism, many destination stakeholders will struggle to resume pre-crisis operational capacity and productivity. If an afflicted destination's tourism sector is to remain viable it must restore consumer confidence.

\section{Recovery from crisis}

The length of any particular crisis and associated recovery period can vary substantially. Impacts are multidimensional and can be difficult to quantify or assess including, medical and emotional recovery of victims, economic and social losses and physical/environmental damage (Cuny, 1983). When a hazard has compromised public risk perceptions, effective recovery for the tourism sector and associated stakeholders requires extensive image rebuilding.

The WTO (2003) suggests that at the most fundamental level, the management of information and related media should continue to address consumer concerns about safety and security. Subsequent investigations, improvements to operational practices and systems, law enforcement and preventative measures should similarly be reported on in a timely and objective manner. Experience reveals that the diversion of major transport carriers, insurance restrictions, and the introduction of international travel advisories can be particularly damaging to a destination.

Reliant on good public relations, an adversely affected tourism destination typically needs to embark on new, improved and often aggressive destination marketing and promotional campaigns (Bierman, 2003; Glaesser, 2003).

Negative publicity such as media coverage conveying loss of life, human suffering, broad scale disruption and/or extensive damage should be amended to provide positive images and impressions. Confidence building measures such as celebrity visits, journalist familiarisations and staging 
international events are often employed to influence the subjective opinions and attitudes of potential consumers. Supplementary actions include the diversification of product base, targeting new market segments and improving the levels of both quality and competitiveness. (UNEP, 2002)

While restoring faith in the destination is considered essential for the recovery of the tourism sector, it traditionally requires substantive cooperation, direction and fiscal collaboration. Without adequate support from government, private enterprise and relevant stakeholders, there is no guarantee that a damaged tourism sector will be fully rehabilitated. Given the diversity and choices afforded by the industry, it is unrealistic to rely on customer loyalty or the natural assets of a destination to re-establish conditions following a significant crisis. While discounting and incentives may afford short-term gains, commitment and substantial investment are considered necessary to ensure that such strategies also produce medium to long-term benefits. Effective recovery strategies need to be focused on more comprehensive and sustainable outcomes. Consistent with the ISDR (2004) definition of disaster recovery the process implies "decisions and actions taken after a disaster with a view to restoring or improving the pre-living conditions of the stricken community, while encouraging and facilitating necessary adjustments to reduce disaster risk" (p. 7).

In holistic crisis management terms, the recovery process can also provide opportunity. The experiences and lessons learnt should be evaluated and utilised to develop improved strategies to mitigate future crisis. For destinations that are heavily reliant on tourism, such reforms imply significant economic, social and structural investment. Susceptibility may also be reduced through improvements to existing facilities, institutions and an increase in self sufficiency.

\section{Sustainable development and tourism}

While a crisis may highlight the underlying vulnerability of any destination strongly focused around the tourism industry, the restructuring necessitated by crisis recovery can provide the opportunity to adopt a more holistic and sustainable approach to tourism and development. Sustainability implies an integrated, participatory process which fairly balances social, economic and environmental interests (WTO, 2004; UNEP, 2002).

Traditionally, tourism development has been driven by governments, businesses, corporations and large scale organisations, with limited public input or consultation. While communities may benefit from associated infrastructure, employment and income, such enterprises and investments are often focused on realising a financial agenda. Sustainable tourism 
development ideally accommodates and empowers all interested parties in both formal and informal tourism structures. Through an inclusive, consultative and coordinated approach to development, it proposes that it is possible to secure a more equitable distribution of benefits for all segments of the population.

Such development and restructuring within the tourism sector may be guided by representative decision making forums including participants from the national tourism structures, the police, the public, the business community, vendors, tourist information agencies and any other pertinent stakeholders. In achieving effective horizontal and vertical integration, resolutions regarding delegation, responsibilities and subsequent implementation need to be consensus-based and compatible with community goals. Control, transparency and accountability are considered integral to an open process. In addition, construction and/or maintenance of an integrated tourism crisis management strategy would be essential.

Many of the social and economic impacts following a crisis are indicative of the extent to which a destination has become reliant on tourism. When committing significant recovery resources into destination marketing, promotion and restructuring it is necessary to consider the inherent vulnerability of the industry. Adversity resulting from any tourism crisis may actually be reduced by less direct dependence on tourism generated income and revenues. Assistance and funding provided to help a destination recover may alternatively be used to accomplish other community aspirations and priorities, such as improved education and social conditions. Recommended strategies include enhanced self-sufficiency, resilience and diversification of the economy (Bloom, 1996).

Achieving the ideal of social, economic and environmental sustainability needs a committed and democratic approach to both development and governance. Extensive understanding, awareness, training and education are required at all levels. The successful operation of sustainable strategies and practices in both community development and the tourism sector should ultimately reduce a destination's vulnerability to crisis.

\section{From theory to practice}

While neither tourism crises or destination vulnerability are new phenomena, Robert and Lajtha (2002) assert that crisis management, as a science, is still in its infancy largely due to the difficulties in measuring, standardising, and comparing one crisis situation with another. Each hazard situation and destination is unique, and as such circumstances may never be effectively simulated or replicated. In developing improved strategies to 
facilitate destination crisis management, recovery and sustainability it is necessary to understand both the relevance and application within a real context. Case studies of afflicted destinations may similarly provide many tangible lessons of utility to other vulnerable host communities.

\section{Bali - a case study of a tourism crisis in a tourist-reliant destination}

Bali, often referred to as 'Paradise on Earth', is a small island located in the tropical Indonesian archipelago. Renowned for its vibrant indigenous culture, diverse natural attractions and capacity to cater for almost any class and budget of traveller, it rapidly grew into a popular and well patronised international tourist destination. The impact and subsequent events triggered by the terrorist bombings of 12 October 2002, rapidly and effectively undermined this burgeoning tourism industry. As the vulnerability and socio-economic significance of this sector became more apparent, the community of Bali has been faced with a long and difficult road to recover from tourism crisis.

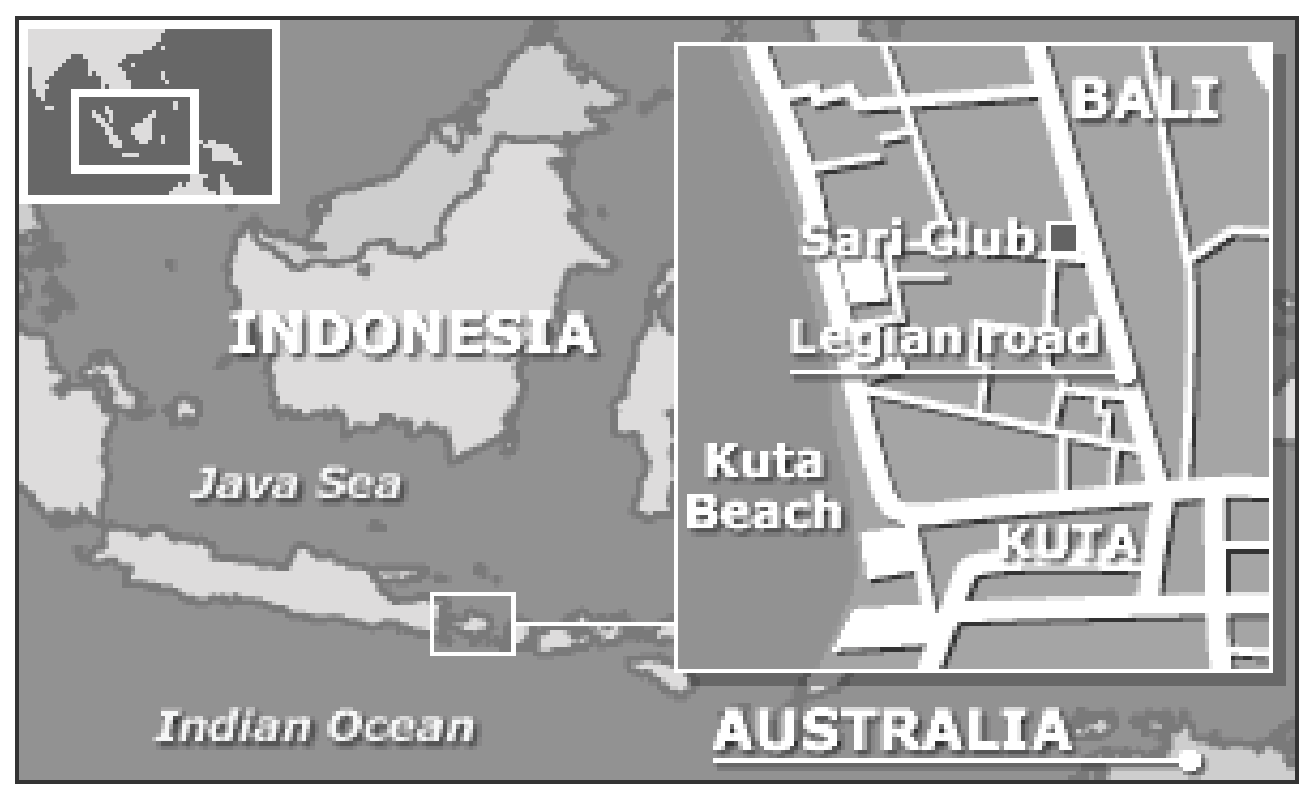

Figure 6.2

Location of the terrorist attacks in Kuta, Bali, 12 October 2002 Source: Bali SOS, 2002

\section{The context - tourism reliance and vulnerability}

While travellers' interest in Bali is not a new phenomenon, the island only gained popularity as an international destination during the late $1960 \mathrm{~s}$ 
(Kalla, 2003; UNDP, 2003). To further encourage visitor growth, the Indonesian government actively pursued tourism-specific development plans that included the construction of an international airport. However, through a subsequent lack of public consultation or regulatory control most urbanised areas in southern Bali rapidly expanded beyond government influence. Locations such as the former fishing village of Kuta/Legian, grew to be overcrowded and over-commercialised. Many rural Balinese and other Indonesians enticed by the social and economic prospects of anticipated tourism earnings chose to abandon traditional pursuits and activities to migrate to such areas. Through the supply of food, natural and cultural attractions, arts, and other commodities and services, most of Bali came to benefit from development of this industry. An increasing reliance on these social and economic gains however, also established a significant level of dependence on commercial tourism.

Whether as a legacy of its geographical location or predominant belief in karma and harmonious balance; Bali had always been perceived as safe, tranquil and immune from the problems and instability that have affected other regions (World Bank, 2003). Residents (with the exception of some persistent touters and hawkers) are renowned for their calm friendly attitude and easy smiles. Travel features display images of religious and cultural festivities, rice fields, sunsets and extensive accommodation and tourist facilities.

While tropical climate conditions and a diverse terrain mean the island is susceptible to natural hazards (including landslides, drought and volcanic eruption) it had never been perceived as a high-risk destination. The possibility of travel accidents, disease and transportation delays were generally accepted as common hazards of overseas travel. Similarly as the island's residents, businesses and government authorities conducted their various daily activities little thought or investment had ever been given to the idea of significant crisis.

\section{Bali in crisis - the trigger and response}

At approximately 11:20pm the night of 12 October 2002 the peace and ambience of Bali were shattered by two explosions at crowded nightclubs on the popular tourist entertainment strip of Jalan Legian (Legian Street), Kuta. In the chaos and destruction that followed it became apparent that the emergency services of Bali were ill-prepared and ill-equipped to deal with such a disaster (Bali Recovery Group, 2003). There was no operational emergency/crisis management plan - either generic or tourism related. Immediate response actions were focused on the basic instinct to protect life and property. Even with the dedication and efforts of available emergency 
response crews, hospital staff and volunteers, there were numerous fatalities (a final death toll of 202), mass casualties of varying severity, and extensive physical damage. With victims from 22 countries and rampant speculation of terrorism, this incident quickly gained a high profile and global media status. Images and stories of the carnage, the extensive devastation, inadequate medical facilities and raw emotion were rapidly and prominently presented on television, radio, in print and via the Internet.

Overwhelmed Indonesian government authorities were quick to express sympathies and reassure visitors of personal safety, but were unable to successfully control or direct the ensuing media reports. Lacking a singular spokesperson or media centre any credibility was effectively undermined by instances of confusion and contradiction. Local community groups instituted street patrols while official safety measures and crime investigations were implemented by both the police and military. As financial aid, medical expertise and technical assistance was made available from around the world, the Bali Recovery Group (a coordination committee of existing local non-government organisations), was created with the aim to deliver the best services, collect data and minimise duplication of effort. With most of the immediate medical needs soon assuaged, official strategies began to focus on the clean up and restoration of vital functions of the community.

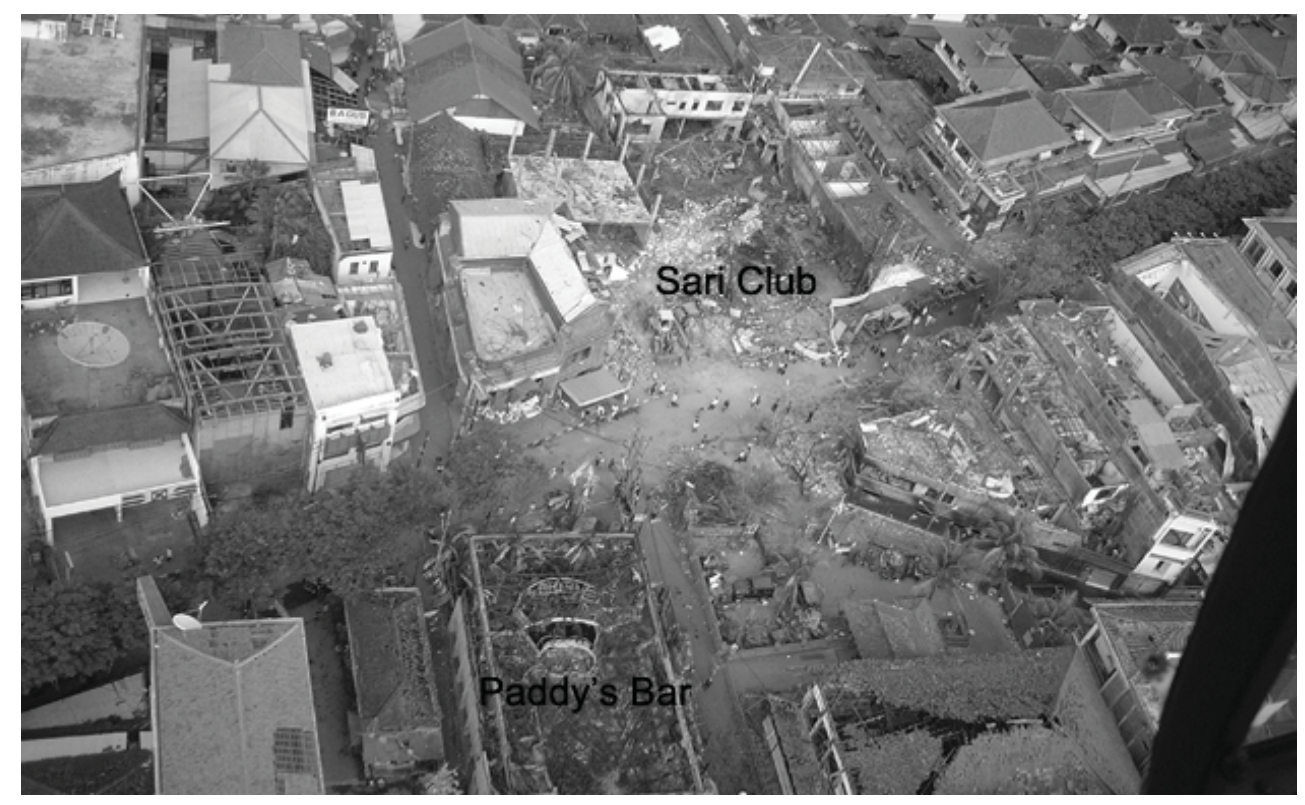

Figure 6.3 Aerial view of the damage caused by the explosions at Paddy's Bar and the Sari Club

Source: courtesy of Steve Palmer, November 2002 


\section{Rehabilitation: short-term initiatives}

While formal efforts were made to remove and analyse the structural debris it became quickly apparent that the explosions were planned by terrorists, intentionally and specifically targeting tourism in the area. International travel warnings/bans were immediately upgraded as most of the remaining tourists abandoned the island and surrounding region. Already affected by the economic slowdown caused by the 1998 election riots and the 11 September 2001 attack on the World Trade Center, Bali was effectively plunged into a tourism crisis (Kalla, 2003; Karyadi, 2003; World Bank, 2003). In a period that traditionally coincided with peak season, direct tourist arrivals dropped, occupancy rates decreased to single figures and associated earnings plummeted. Residents struggling with the emotional, psychological and even physical effects of the bombing were now faced with the disruption of their livelihoods.

In the days and weeks that followed all stakeholders were genuine and concerted in their efforts to minimise the socio-economic impacts. Government measures focused on a commitment to security and law enforcement, tourism promotion and the provision of a social safety net (World Bank, 2003). The Bali Recovery Group (2003) worked predominantly towards direct victim and family support - medical, financial and educational. Most hotels and businesses laboured toward the resumption of services and the restoration of Bali's tourist image, although efforts were rarely coordinated. Meanwhile, individuals and families within the community were forced to implement short-term coping mechanisms such as return migration to the villages, selling assets, reducing household expenditure and accessing savings. While there were growing concerns about reprisals against Muslims and related ethnic tension, few incidents were reported. Special non-denominational religious 'cleansing' rituals were held to help restore balance to both the physical and spiritual world.

As foreign visitor arrivals remained low in early 2003, successful marketing strategies led to an increase in domestic visitors and an expansion of the Asian market segment (UNDP, 2003). Air Paradise, a locally owned airline, commenced flights to Australia in an effort to help revive visitor numbers. Locally and regionally, security became the top priority as a new policing policy focused on greater visibility and upgrades to existing measures at all ports of entry. Several international events and tourist operator/journalist familiarisations were also presented to increase the profile of Bali and assurances of safety and security. Despite such strategies, businesses and the community continued to suffer. As operational costs surpassed income, hotels, restaurants, shop fronts and transport providers faced closure and/or bankruptcies. 
Residents experienced job cut-backs, unemployment/underemployment, income reduction and diminishing social standards. As reduced business and tourism revenues resulted in less expendable income for the communities of popular resort areas, residents were forced to change their usage and consumption habits. The effects and influence of such reduced spending gradually spread throughout the island's economy and conditions in the poorer areas of Bali deteriorated; this is sometimes referred to as the 'ripple effect'.

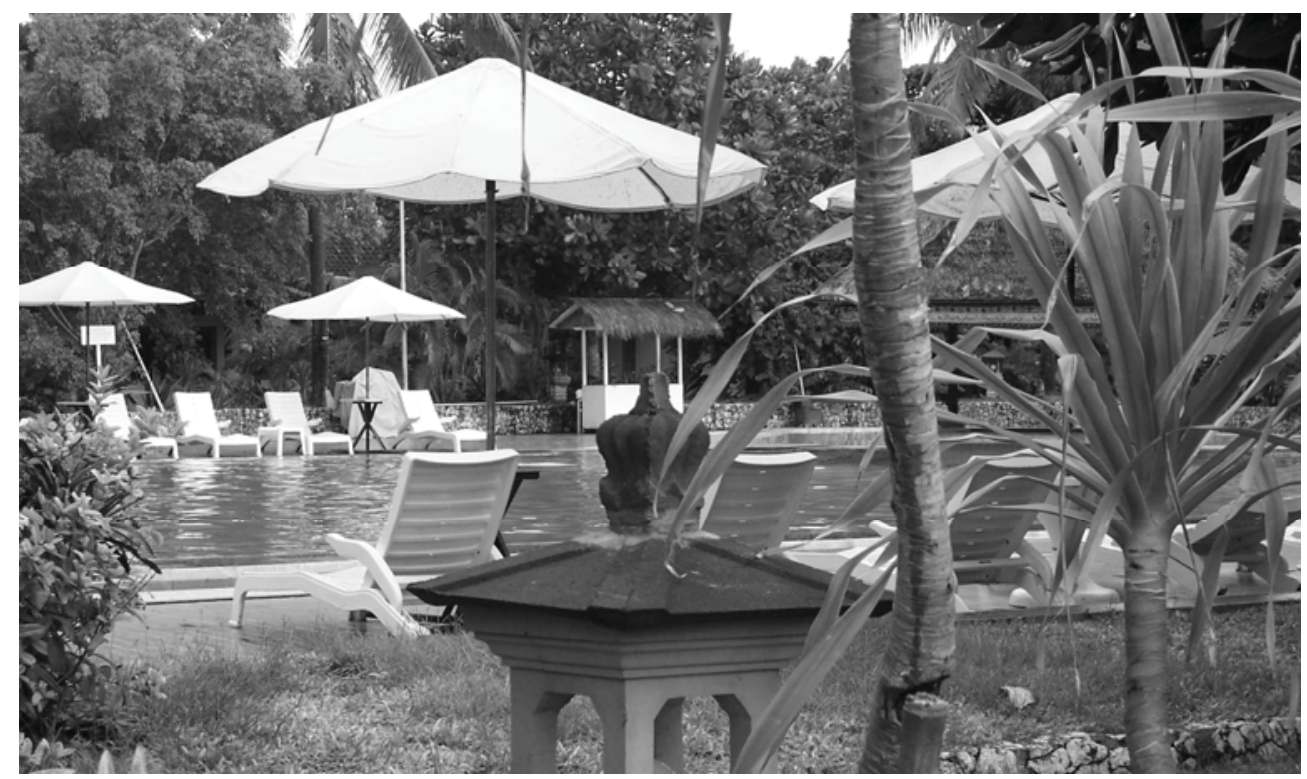

Figure 6.4 Tourism crisis - a deserted hotel pool-side in Kuta, January 2003

\section{Reconstruction to recovery}

As mandatory work permits and hotel accreditation standards were introduced to improve accountability, international travel concerns regarding the risk of contracting SARS and the war in Iraq seem to have minimised any initial improvements in direct visitor arrivals. While the national government introduced new anti-terrorism initiatives and secured the convictions of the Bali bombers, the August 2003 terrorist bombing of the Marriott Hotel in Jakarta quickly undermined any progress regarding perceptions of improved safety. Despite such events and the continued travel advisories, by the end of the year visitor numbers were increasing and gradual improvements occurred in tourism business prospects. The oneyear anniversary of the attacks and associated memorial services successfully attracted much international media attention and publicity, yet for many it 
only revived the issue of terrorism rather than promoted the merits of the island.

January 2004 was a record month for foreign visitor arrivals to Bali, but closer investigation of the associated socio-economic statistics revealed a different story. Benefiting from the discounts, sales and bonus incentives offered by tourism providers, visitors were actually staying for shorter periods of time and spending less money, minimising business profit margins. The Indonesian Government's controversial introduction of a new visa fee in February 2004 was met with further disdain by both consumers and operators. As few of the post-bombing donor agencies remained operational in Bali, many community members were forced to sell more personal possessions and property as a means of coping. A large number of the programs introduced to increase economic diversification and social support eventually collapsed due to lack of adequate investment, commitment and finances. Numerous reports have suggested that through this experience of shared adversity many traditional and familial support networks were strengthened (Hitchcock \& Darma Putra, 2005). While tourist numbers suggested a return to pre-crisis levels, a further bombing outside the Australian Embassy in Jakarta in September 2004, again added uncertainty to a delicate market.

While the devastating Indian Ocean tsunami on 26 December 2004 did not directly impact on the island of Bali, many tourist operators reported that subsequent cancellations were caused by a geographical association with the Indonesian province of Aceh. As former recipients of aid, the empathetic community and non-government organisations of Bali reactivated many support networks to provide resources and assistance for the tsunami victims. With a return of economic stability for many residents, programs were also established to support more local community health centres and improved access to public education. Whether as a consequence of successful marketing and promotion, the inherent attributes of the island or a diminishing risk perception, in 2005 there were unprecedented numbers of direct visitor arrivals to Bali. Even the controversy surrounding several high profile 'foreigner' drug cases failed to dissuade most tourists. While this new market segment consisted of less long-haul European and North American tourists, Australians had again returned to this popular 'playground' supplemented with travellers from throughout regional Asia. For many Balinese this restoration of business and profits heralded the end of a difficult period. 


\section{Crisis revisited}

During September 2005 the highest ever number of direct arrivals was recorded (Table 6.1), but on 1 October 2005 the island was again subjected to the tragedy of tourist-focused terrorism. Although the explosions in restaurants of Kuta Square and Jimberan Bay were significantly smaller (25 fatalities) than the previous incident, subsequent international media attention was quick to surmise a pattern for premeditated violence against tourists. Having learnt from past experience, medical personnel and authorities were quick to respond, establishing an emergency centre at the Sanglah Hospital with an effective media capacity. The Chief of Indonesian Police General Made Pastika, who had been seen as responsible for capturing the perpetrators of previous bombings, was quickly presented as the official spokesman to address questions and make any formal statements. Familiar with the potential needs of the victims and their families, community-based volunteer and support networks were assisting within the hour.

While travel advisories were reinstated and large numbers of tourist chose to avoid Bali, cancellations were not as dramatic as following the 2002 attacks. Maintaining occupancy rates of between 40-50\% many analysts have drawn the cautious conclusion that perhaps the travelling public are becoming more accepting of terrorism as a risk of modern day travel. As visible safety and security again became a high priority, the Bali Hotel Association together with several other private enterprise stakeholders made substantial financial commitments to supplement security upgrades. Despite the level of destination loyalty, lower visitor numbers again precipitated socio-economic hardship for the host community, exacerbated by the subsequent collapse of the locally owned airline, Air Paradise. With international uncertainty regarding the probability of further attacks, many have also been critical of Indonesian government's slow commitment to Bali's tourism recovery efforts. With profits and revenues again lagging the Governor of Bali formally announced the establishment of a Bali Security Council in October 2005 with membership including the police, military, academics, nongovernmental agencies, government bureaucrats, and community leaders. Part of this group's responsibility is intended to support a wide range of tourism promotion, recovery and security issues. 
Table 6.1 Direct foreign tourist arrivals in Bali 2001-2005

\begin{tabular}{|l|c|c|c|c|c|}
\hline & $\mathbf{2 0 0 1}$ & $\mathbf{2 0 0 2}$ & $\mathbf{2 0 0 3}$ & $\mathbf{2 0 0 4}$ & $\mathbf{2 0 0 5}$ \\
\hline January & 92,604 & 87,027 & 60,836 & 104,062 & 101,931 \\
February & 104,083 & 96,267 & 67,469 & 84,374 & 100,638 \\
March & 110,582 & 113,553 & 72,263 & 99,644 & 117,149 \\
April & 109,634 & 104,960 & 53,726 & 111,021 & 116,272 \\
May & 103,939 & 119,284 & 47,858 & 117,191 & 116,615 \\
June & 122,352 & 130,563 & 81,256 & 131,685 & 136,369 \\
July & 142,946 & 147,033 & 111,828 & 148,086 & 158,453 \\
August & 144,324 & 160,420 & 115,546 & 155,000 & 157,229 \\
September & 104,008 & 150,747 & 106,763 & 141,900 & 162,102 \\
October & 129,932 & 81,100 & 97,435 & 128,297 & 81,109 \\
November & 110,145 & 31,517 & 83,853 & 110,471 & 62,705 \\
December & 102,290 & 63,393 & 94,196 & 125,376 & 75,877 \\
\hline \hline Total & $1,376,839$ & $1,285,864$ & 993,029 & $1,457,107$ & $1,386,449$ \\
\hline
\end{tabular}

Source: BPS Statistics Indonesia, 2006

Table 6.1 indicates the fluctuations in visitor numbers which reflect the market sensitivity to external events such as the 11 September 2001 attacks, the 12 October 2002 bombings, SARS, the Jakarta bombings and further attacks on 1 October 2005.

\section{Lessons in crisis management and recovery}

While Bali has a unique context, it presents many lessons of value to any popular tourist destination. As Australian tourists comprised a significant proportion of victims in both terrorist attacks, the Australian Government and national tourism authorities have also been forced to face the reality that terrorism can happen to anybody, anywhere and anytime. The most apparent message from this experience is that no destination should consider itself immune to crisis and that preparation and proactive capacity building are more effective than complacency. Irrespective of the type of hazard agent or crisis trigger, there are some universal tenets to effective crisis management. Consistent with the recommendations of peak industry bodies such as the WTO, WTTC and PATA - safety and security, communication, promotion and marketing are integral to positive image and consumer confidence. It may not always be possible to prevent a crisis yet the duration and adverse impacts may be minimised.

In responding to the first terrorist attacks Bali had limited skills, experience or even adequate medical facilities. Although the physical impact area was 
small and security was rapidly improved, the media, officials and even tourism operators failed to convince potential consumers of their personal safety. Subsequent promotion and marketing based on discounts and incentives, while numerically successful, also reduced profit margins. Securing an increase in the domestic and regional market segment to sustain the industry through times of hardship was perhaps one of the most productive tourism strategies. While tourism arrivals gradually increased towards 2005, the influence of numerous external events served to reinforce the erratic and often fickle nature of tourism. Lacking the requisite infrastructure and resources for greater economic diversification the hostcommunity of Bali has been forced to become more adaptable, resilient and self-sufficient. Although the level of tourism reliance remains high, obvious improvements in the response to the second series of attacks reveal a vast improvement in both management and coping capacity. Consistent with the concept of enhanced sustainability further time will reveal the success of current endeavour towards greater stakeholder integration, participation and collaboration.

\section{Conclusion}

Like many destinations throughout the world, the tourism industry in Bali was developed in a generally unsustainable manner. While prosperity generated significant opportunities, limited consideration was given to the risks of market instability and growing levels of socio-economic reliance. Faced with the reality of tourism crisis and adversity, this unsuspecting host community was forced to adopt purely reactive response strategies. Lacking the relevant experience, knowledge and skills, the popular tourist island Bali has experienced a difficult path to re-establish its market stability. As unrelenting external events have reaffirmed the inherent vulnerability of any popular destination and its stakeholders, an improved resilience and coping capacity demonstrates the value of employing effective formal and informal crisis management strategies. 